\title{
The pyogenic granuloma: an unusual presentation and localization
}

\begin{abstract}
Pyogenic granuloma is a hyperactive benign inflammatory lesion arises in response to various stimuli such as low-grade local irritation, traumatic injury, hormonal factors, or certain kinds of drugs. It's usually affects skin and mucous membranes. It typically manifests as an erythematous nodule that bleeds on contact. The dermoscopy is very specific. The histological study often contributes to the diagnosis. The management depends on the severity of the symptoms. We report a particular case of granuloma pyogenic by its mode of occurrence and location.
\end{abstract}

Keywords: pyogenic granuloma, tongue, dermoscopy, histology, surgery

\author{
Volume 2 Issue 2 - 2018 \\ O El Jouari,' S Gallouj, ${ }^{2}$ G Senhaji,' A \\ Lamouafeq,' M Rimani, ${ }^{3}$ Fz Mernissi' \\ 'Department of Dermatology and Venereology, University \\ Hospital Hassan II, Morocco \\ ${ }^{2}$ Faculty of medicine, University Hospital Hassan II, Morocco \\ ${ }^{3}$ Hassan center of Anatomopathology, University Hospital \\ Hassan II, Morocco
}

Correspondence: $\bigcirc$ El Jouari, Department of Dermatology
and Venereology, University Hospital Hassan II, Fes, Morocco,
Email eljouariouiame@gmail.com

Received: March 13, 2018 | Published: April 10, 2018

\section{Introduction}

Pyogenic granuloma is the most common of all the oral tumor like growths. ${ }^{1}$ Pyogenic granuloma is a hyperactive benign inflammatory lesion witch arises in response to various stimuli such as low-grade local irritation, traumatic injury, hormonal factors, or certain kinds of drugs. ${ }^{1}$ It usually affects skin and mucous membranes. We report a particular case of granuloma pyogenic that occurred with no history of trauma in the midline of the dorsum of tongue, which is a rare site of this tumor.

\section{Case report}

A 61-year-old man was referred for a papular lesion, appeared approximately 4 months earlier in the midline of the dorsal surface of the tongue, having progressively increased in size, asymptomatic, without any notion of trauma or contact bleeding just a poor oral hygiene. The dermatological examination showed a very limited nodule measuring $1 \mathrm{~cm}$ with regular contours, firm in consistency, with a ceiling base, not infiltrated at the median line of the dorsum of the tongue (Figure 1). The rest of the somatic examination was without anomaly. Dermoscopy showed irregular whitish-yellow amorphous structure (Figure 2). The main differential diagnosis was melanoma. After local anesthesia, the lesion was excised deeply (Figure 3). Histology reported an ulcerated epidermis, covered with a fibrinoleucocyte coating. The ulceration overhangs an oedematous granulation tissue rich in congestive neovascular, turgescent endothelium. There is associated a polymorphic inflammatory infiltrate. The epidermal coating on the edges of the ulceration presents a reactional hyperacanthosis with papillomatosis and parakeratosis, including damp squames (Figure 4). The patient was followed the patient was followed for 12 months. No recurrence was noted.

\section{Discussion}

Oral pyogenic granuloma has a predilection for the gingiva $(75 \%$ case). ${ }^{2}$ It accounts for 1.85 to $7 \%$ of all biopsy findings from oral cavity lesions. ${ }^{3}$ It is now universally agreed that this lesion is formed as a result of an exaggerated localized connective tissue reaction to a minor injury or any underlying irritation. ${ }^{4}$ Clinically, the appearance of pyogenic granuloma is red/pink to purple, and can be smooth or lobulated mass which may be pedunculated or sessile. It grows in size up to several centimeters in size but is usually less than $2.5 \mathrm{~cm}$. Pyogenic granuloma can grow rapidly and will often bleed profusely with little or no trauma. ${ }^{5}$ Dermoscopy of pyogenic granuloma generally shows a typical pattern characterized by a red to dark pink homogeneous area, surrounded by a white collarette; additional findings include white lines intersecting the lesion and ulcerations. ${ }^{6,7}$ In our case, dermoscopic examination did not show any of these patterns, but instead a central irregular whitish-yellow amorphous structure with a peripheral crown of polymorphous atypical vessels. Histopathologically, pyogenic granuloma usually presents with granulation tissue in a delicate fibrillar stroma with inflammatory cells and proliferating capillaries and endothelial cells. Usually the duration of the tumor expresses the extent of vascularity and fibrosis. ${ }^{8}$ Mature pyogenic granuloma losses its vascularity and becomes more fibrous and resembles an irritation fibroma. ${ }^{9}$ The management of the granuloma depends on the severity of the symptoms. If the lesion is small, painless and without bleeding, monitoring with hygiene measures is recommended. While if the lesion is large, painful and bleeding, a deep conservative surgery is strongly advised with eviction of irritants. $\mathrm{CO}_{2}$ and ND-YAG lasers have also proven effective with minimal bleeding risk. Recently, Timoptol has been successfully used, but surgery remains paramount for cases requiring histological control. ${ }^{10}$

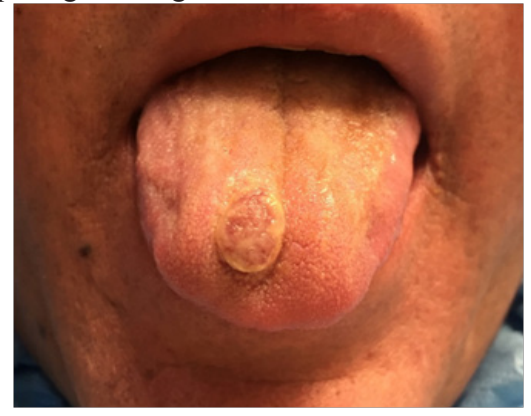

Figure I A nodule sitting on the median line of the tongue 


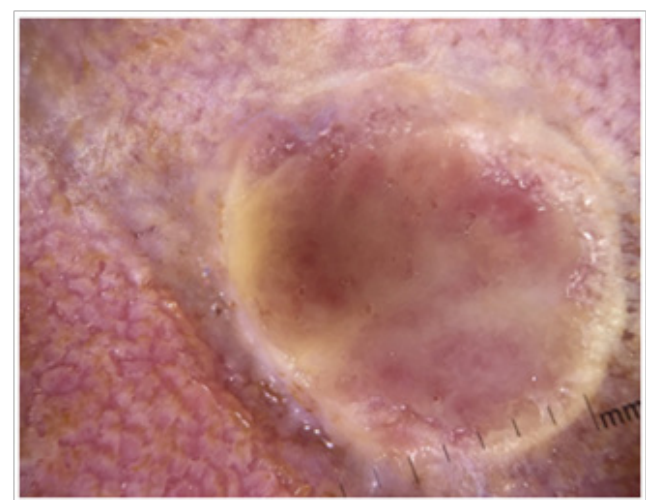

Figure 2 Dermoscopic image irregular whitish yellow amorphous structures, without specific vascularization.

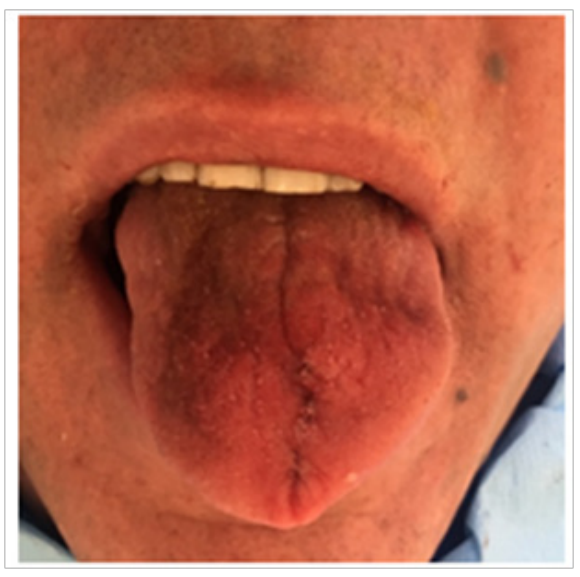

Figure 3 After a complete surgical excision of the lesion.

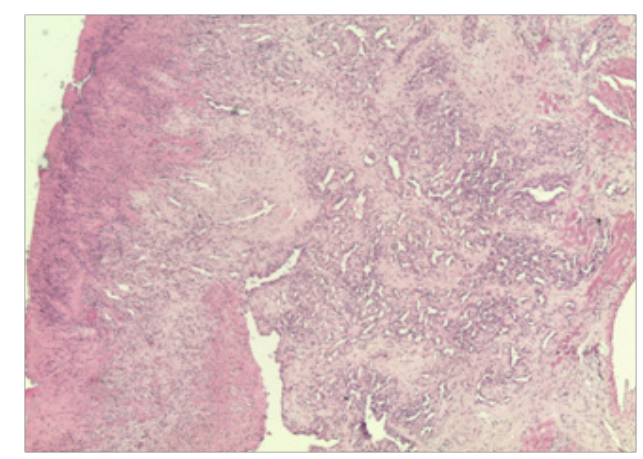

Figure 4 HES stain Gx50-> Ulceration with vascular lobulated Proliferation

\section{Conclusion}

Oral pyogenic granuloma is a common lesion in the oral cavity. Its localization in the tongue is rare especially outside the lateral edges. A careful management of the lesion also helps in preventing the recurrence of this benign lesion.

\section{Acknowledgements}

None.

\section{Conflicts of interest}

The author declared no potential conflicts of interest with respect to the research, authorship, and/or publication of this article.

\section{References}

1. Verma PK, Srivastava R, Baranwal HC, et al. Pyogenic Granuloma - Hyperplastic Lesion of the Gingiva: Case Reports. Open Dent J. 2012;6:153-156.

2. Akyol MU, Yalçiner EG, Doğan AI. Pyogenic granuloma (lobular capillary hemangioma) of the tongue. Int $J$ Pediatr Otorhinolaryngol. 2001;58(3):239-241.

3. Lawoyin JO, Arotiba JT, Dosumu OO. Oral pyogenic granuloma: a review of 38 cases from Ibadan, Nigeria. Br J Oral Maxillofac Surg. 1997;35(3):185-189.

4. Mathur LK, Bhalodi AP, Manohar B, et al. Focal fibrous hyperplasia: a case report. Int J Dent Clin. 2010;2(4):56-57.

5. Sachdeva SK. Extragingival Pyogenic Granuloma: an Unusual Clinical Presentation. J Dent (Shiraz). 2015;16(3 Suppl):282-285.

6. Zaballos P, Carulla M, Ozdemir F, et al. Dermoscopy of pyogenic granuloma: a morphological study. Br J Dermatol. 2010;163(6):12291237.

7. Micali G, Lacarrubba F, Massimino D, et al. Dermatoscopy: alternative uses in daily clinical practice. $J$ Am Acad Dermatol. 2011;64(6):11351146.

8. Muruganandan J, Sivakumar G, Sujatha G. A large pyogenic granuloma developing into a peripheral ossifying fibroma: A case report and discussion. I Jou Mul Dent. 2011;1:342-346.

9. Regezi JA, Sciubba JJ, Jordan RC. Oral Pathology: Clinical Pathological Considerations. 4th ed. Wb Saunders : USA; 2003. p. 115-116.

10. J Durairaj, K Balasubramanian, PR Rani, et al. Giant lingual granuloma gravidarum. J Obstet Gynaecol. 2011;31(8):769-770. 